\title{
ARQUIVO PALMA MUNIZ: UM NOVO ESPAÇO PARA A PESQUISA
}

\author{
Ana Negrão do Espírito Santo \\ Arquivo Público do Estado do Pará \\ José Maia Bezerra Neto \\ Depto. de História/UFPA \\ Instituto Histórico e Geográfico do Pará-IHGP.
}

Fundado em 03 de maio de 1900, o Instituto Histórico e Geográfico do Pará, distintamente do IHGB, surgiu em plena república, reunindo diversos integrantes da intelligentzia e personagens políticas destacadas da sociedade da borracha, no Estado do Pará ${ }^{~}$.

Visando a construção de uma história e memória da mesma, marcadamente événementielle, o IHGP acabava preservando os valores conservadores dos grupos sociais hegemônicos na sociedade paraense da época em que foi estruturado, não sendo, inclusive, evento isolado: no mesmo período, havia sido fundada a Academia Paraense de Letras, segundo o modelo francês, culminando o processo de efervescência cul-

\footnotetext{
${ }^{1}$ Acerca do perfil institucional do IHGB, ver SCHWARCZ (1993). Consultar também GUIMARÃES (1988) e COELHO (1981). As análises construídas sobre o papel do IHGB na historiografia nacional constituem-se sugestivas para uma reflexão acerca do IHGP.
}

tural e literária por qual passava a cidade de Belém, principal cidade do norte do país, durante os anos da folies du latex (AZEVEDO, 1990).

É verdade, entretanto, que o IHGP não conseguiu manter-se consolidado, esvaindo-se em pouco tempo. Somente em 1917, foi reinstalado, passando a ocupar papel de destaque na produção do conhecimento da história regional, reunindo em suas fileiras os nomes tradicionais e geralmente consagrados da historiografia paraense, como por exemplo: Domingos Antônio Rayol; Palma Muniz; Ernesto Cruz; Jorge Hurley;.....

Nesta perspectiva, a publicação da revista do IHGP e a preocupação com a guarda de volumosa obras bibliográficas (biblioteca), de variado acervo iconográfico (museu), e, particularmente, importante documentação manuscrita e impressa, datada desde as primeiras décadas do século XVIII, de origem diversa (arquivo), enquadravam-se nos propósitos do IHGP como guardião oficial da memória e história 
pátria e regional. Inclusive, formando as bases de constituição de sua biblioteca, museu, e arquivo, conforme estipulava os artigos $45^{\circ}, 46^{\circ}, 47^{\circ}$, e $48^{\circ}$, do Capítulo VIII dos Estatutos da instituição.

Acontece que, a proposta de organização da biblioteca, museu, e arquivo, concomitantemente à aprovação de suas regras de funcionamento e objetivos, constantes do Capítulo VIII dos Estatutos do IHGP, não conseguiu sair do papel, permanecendo seu vasto e variadíssimo acervo em completa desorganização, particularmente, as fontes documentais, datadas do início do século XVIII, que até pouco tempo vinham sofrendo impiedosamente a ação do tempo, da umidade e das traças, haja vista a situação em que se encontravam as mesmas, ou seja, acondicionadas em uma pequena sala sem iluminação, ventilação, ou outro qualquer ambiente favorável à sua conservação, sem sequer um arrolamento destas, mesmo que precário, enfim condenadas à destruição corrosiva da falta de cuidados recomendados pela prática arquivística.

Dentro deste quadro de cores tão tristes, fez-se necessário a efetivação do projeto de organização do Arquivo do IHGP e inventariamento das suas fontes documentais, preservando parte de nossa memória, bem como possibilitando a sua consulta e manuseio, por parte do público, quer especializado, quer leigo. Entretanto, façamos uma pausa para explanação sobre as condições físicas do prédio-sede do IHGP, na qual encontra-se o referido acervo, para posteriormente retomarmos o histórico de organização desta documentação, explicitando a mesma ao público interessado.

$\mathrm{Na}$ antiga rua Tomázia Perdigão ${ }^{\circ} 62$, atual D'aveiro Cidade-Irmã, no bairro da Cidade Velha, situado à Pça. Dom Pedro II, outrora Largo do Palácio; Largo da Constituição; e, Largo da Independência; existe o imponente Solar do Visconde de Arary e Barão de Guajará, sede-própria do IHGP.

Construção arquitetônica da primeira metade do século XIX, caracterizada pelo estilo neo-clássico luso-português, serviu como residência da família de
Antônio de Lacerda Chermont (Visconde de Arary), e, posteriormente, da família de Domingos Antônio Raiol (Barão de Guajará). Morto o último, em 1912, o prédio continuou como patrimônio familiar até que, em 1942, através de Pedro Raiol, filho do Barão, foi vendido à Prefeitura Municipal de Belém, na gestão do Prof ${ }^{\circ}$ Abelardo Leão Condurú .

Em 1943, sendo interventor federal no Pará, Joaquim Cardoso de Magalhães Barata, "em face da resolução n ${ }^{\circ} 2.244$ de 6 de novembro de 1943, do Conselho Administrativo do Estado, foi baixado o decreto municipal n ${ }^{\circ} 168$, de 10 de novembro de 1944, em que o prefeito Alberto Engelhard efetuou a doação de móveis, biblioteca e prédio do Solar do Barão de Guajará ao Instituto Histórico e Geográfico do Pará, nessa época sob a presidência do Desembargador Henrique Jorge Hurley" (TRINDADE, 1995, p. 12).

Situado na Cidade Velha, a sede do IHGP encontra-se inserida em área "considerada como o miolo do Centro Histórico de Belém, tombado pela Lei Orgânica de 30 de março de 1990, que em conjunto com o seu entorno é protegido pela lei $\mathrm{n}^{\mathrm{o}} 7.709$ de 18 de maio de 1994, que define categorias de preservação, normas e colocação de letreiros"(TRINDADE, 1995, p. 03). Neste sentido, o antigo Solar do Visconde de Arary e Barão de Guajará, constitui-se parte integrante do patrimônio histórico e arquitetônico da cidade de Belém, sendo inclusive seu tombamento determinado desde 1943, entretanto, efetivado em 23 de maio de 1950, através do Serviço do Patrimônio Histórico e Artístico Nacional (SPHAN) ${ }^{3}$.

Desde então, a sede do IHGP sofreu diversos reparos e obras de conservação e manutenção, destacando-se a restauração empreendida pela Secretaria

\footnotetext{
${ }^{2}$ Sobre as origens e estilo arquitetônico do prédio-sede do IHGP, ver TRINDADE (1995) e Monteiro (1995).

${ }^{3}$ Acerca do processo de tombamento, ver TRINDADE (1995) e MONTEIRO (1995)
} 
de Viação e Obras Públicas do Governo do Estado, em maio de 1969, que durou cerca de um ano, acontecendo a reinauguração do prédio em 10 de abril de 1970, durante a presidência do historiador Ernesto Horácio Cruz, no IHGP. A partir daí, somente em 1984, ocorreu novo empreendimento de restauro, executadas e financiadas pelo SPHAN/Pró-Memória, concluída em fins de 1985. Por outro lado, é verdade, que em 1986 ainda tentou-se ampliar e complementar as obras executadas anteriormente, através da Secretaria de Cultura, Desportos e Turismo, do Governo do Estado do Pará, em conjunto com a Direção Regional do SPHAN/Pró-Memória, que acabaram infelizmente inconclusas.

Neste prédio, portanto, em seu primeiro pavimento, na lateral direita, em pequena sala, outrora utilizado como quarto de escravos ${ }^{4}$, encontrava-se empilhada sobre uma mesa grande e outra menor e improvisada, em estado precário, grande parte da documentação sob a guarda do IHGP. Em outro recinto, reservado ao armazenamento de livros, na parte dianteira do Solar, também existia uma determinada documentação posta em caixas, referentes ao Cemitério da Soledade. Como já afirmamos anteriormente, as fontes documentais, basicamente manuscritas, encontravam-se sem nenhum tratamento e acondicionamento adequado à sua conservação, fazendo com que as mesmas necessitassem urgentemente, sob o risco de sua perda irreparável, sofrer um processo de higienização, organização e inventário, ainda, sendo necessário um trabalho mais cuidadoso de restaura-

\footnotetext{
${ }^{4}$ Sobre a "análise do uso e conservação atual do prédio", bem como a referência ao quarto de escravos no primeiro pavimento, consultar TRINDADE (1995). Também, segundo Monteiro (1995), o Barão de Guajará, Domingos Antônio Raiol, realizou diversas transformações no Solar, fazendo por desaparecer "as cavalariças, a prisão dos escravos, a capela da família e parte do terreno dos fundos que é vendida".
}

ção de determinadas peças bastante danificadas pelos inimigos tradicionais dos papéis envelhecidos e sem nenhum cuidado: O tempo; a umidade; as traças e fungos.

Neste sentido, o "Projeto de Organização do Acervo Documental do IHGP", patrocinado pela Fundação Cultural do Município de Belém/FUMBEL, surgiu da necessidade de mudança deste quadro contraproducente ao trabalho do historiador e demais pesquisadores envolvidos, por um motivo ou outro, com o trato da nossa memória através do estudo de determinadas fontes documentais, como por exemplo, os manuscritos da Câmara Municipal de Belém e outras do Pará, desde a primeira década do século XVIII; a documentação encardenada do Corpo de Bombeiros; ou, da Assembléia Legislativa Provincial; enfim, os próprios documentos relativos ao IHGP, que se encontram no acervo desta instituição.

O referido projeto, por outro lado, atuando numa perspectiva interdisciplinar, combinando história e arquivologia, permitiu o treinamento de discentes dos cursos de graduação de história, ciências sociais e biblioteconomia, como estagiários, com a perspectiva de formação de novos pesquisadores habituados à pesquisa empírica e conhecimento da prática arquivística, fato incomum à nossa realidade.

Neste rumo, as ações desenvolvidas dentro do projeto, iniciado em janeiro de 1996, permitiram o mapeamento e levantamento das fontes constantes do acervo documental do IHGP, verificando-se que a quantidade de documentos históricos que precisavam ser levantados e preservados era realmente significativa, principalmente, em termos qualitativos, haja vista sua fundamental importância para subsidiar futuros trabalhos no campo da história, em suas diversas matizes (econômica; social; política; cultural;...); das ciências sociais; da antropologia social; da arquivologia; entre outras.

Observe-se, também, que a expressiva quantidade de documentos encontrados no acervo do IHGP, no período compreendido entre as primeiras décadas 
do século XVIII até os anos setenta da atualidade, relativos a diversos fundos, como a Câmara Municipal de Belém, outrora Senado da Câmara, permitem estudos acerca da história da mesma ou de outros aspectos políticos, sociais e culturais da cidade de Belém; da mesma forma, a consulta dos Livros de Sepultamento do Cemitério de N. S. da Soledade, possibilita pesquisas sob o ponto de vista da história

\section{Bibliografia:}

AZEVEDO, José Eustáchio de. Literatura Paraense. Belém, Fundação Cultural do Estado do Pará Tancredo Neves; Sec. do Estado de Cultura, 1990.

COELHO. Geraldo M. História e Ideologia: O IHGB e a República (1889-1891). Belém, Universidade Federal do Pará, 1981.

GUIMARÃES, Manoel Luís Salgado. Nação e civilização nos demográfica, a partir das séries de enterros realizados neste campo santo. Na verdade, estes fundos e séries documentais constituem-se exemplos de temas, abordagens e questões que podem eventualmente ser estudadas por parte de outros pesquisadores que também venham a se beneficiar dos instrumentos de pesquisa elaborados e divulgados pelo projeto, tal como o Guia do Arquivo Palma Muniz do IHGP (no prelo).

trópicos. Rio de Janeiro, Vértice, 1988.

MONTEIRO, Shirley do Socorro Magalhães. Solar do Barão de Guajará. Belém, 1995. manuscrito.

SCHWARCZ, Lilia Moritz. O Espetáculo das Raças. São Paulo, Companhia das Letras. 1993.

TRINDADE, Elna Maria Andersen. Solar Barão do Guajará. Belém, 1995. digitado.

Endereço: (Prof. José Maia Bezerra Neto) • Av. Serzedelo Corrêa n. ${ }^{\circ}$ 895, ap. $301 ・$ Batista Campos • Belém • Pará • CEP 66.025-240 • Tel.: (091) 223-6636 